\title{
Optimization of non-ionic surfactants for removing emulsified oil from gas condensate oil-water emulsion in $N$ oilfield
}

\author{
Peng Lv ${ }^{1} \cdot$ Yigang Liu $^{1} \cdot$ Yunbao Zhang ${ }^{1} \cdot$ Limei Sun $^{2} \cdot$ Xianxing Meng $^{3} \cdot$ Xianghai Meng $^{1} \cdot$ Jian Zou $^{1}$
}

Received: 4 February 2020 / Accepted: 30 June 2020 / Published online: 7 July 2020

(c) The Author(s) 2020

\begin{abstract}
The aim of the present study was to obtain effective and economical chemical agents for treatment of oily water from $N$ oilfield. Component characterization of crude oil from $N$ oilfield was carried out with gas chromatography-mass spectrometry. Optimization of non-ionic surfactants combined with dissolved air flotation (DAF) for oil removal was investigated. The results show that the crude oil consisted of nine major components which counted for $96.4 \%$ of the total composition, and the first four compounds made up 50\% of the total composition. For the first four compounds, the density difference between water and each individual compound is smaller than the difference between water and normal alkanes with the same number of carbon atoms, while the solubility of these four compounds in water is greater than that of normal alkanes with the same number of carbon atoms. The characteristic of both density and solubility of the crude oil increased the oil water separation difficulty in DAF progress. The oil content in oily water from $N$ oilfield without any treatment was $5285.95 \mathrm{mg} / \mathrm{L}$. The oil content after treatment of DAF without any chemicals was $895.53 \mathrm{mg} / \mathrm{L}$. Non-ionic surfactants $N I S_{1}, N I S_{2}$ and $N I S_{3}$ all were effective for removing emulsified oil in oily water in DAF progress. $1200 \mathrm{mg} / \mathrm{L} N I S_{1}$ combined with DAF was the optimized formulation by the view of efficiency and economy. The formulation could be successfully used as a commercial product in $N$ oilfield.
\end{abstract}

Keywords Oily water $\cdot$ Crude oil $\cdot$ Emulsified oil $\cdot$ Non-ionic surfactants $\cdot$ GC-MS

\section{Introduction}

Oily water is produced in the petroleum industry process, such as drilling, oil recovery, oil gathering and transportation and oil refining. Since unqualified oily water generates pollution to surface and underground, discharging oily water is getting more and more attention (Abdol et al. 2008). Oily water is a special liquid-in-liquid colloidal dispersions classified as O/W emulsions (Raya et al. 2020). The dispersion, aggregation (Mozaffari et al. 2015) and the adsorption (Darjani et al. 2017) phenomenon are the main aspects which related the colloidal kinetic stability. Generally, the

Peng Lv

hilvp@163.com

1 Tianjin Branch of CNOOC (China) Ltd., Haichuang Street 2121, Tanggu, Tianjin 300452, China

2 Shengli Oil Production Plant of Shengli Oilfield Branch Company, SINOPEC, Dongying, Shangdong 257000, China

3 School of Chemistry and Chemical Engineering, Ankang University, Ankang 725000, China solids (Darjani et al. 2019; Mozaffari et al. 2016a, b, 2019), surfactants or functional molecules such as asphaltenes and resins are contributed to the stabilized emulsion(Raya et al. 2020). As an O/W emulsions in a specific oilfield, the factors affecting its stability include the $\mathrm{pH}$ of the wastewater, the temperature, the oil/water content, functional molecules such as asphaltenes and resins, solid content and the kind and concentration of the surfactant. These factors mainly affect the interfacial tension between the oil and water, and the thickness and rheological property of interfacial film (Mozaffari 2015; Mozaffari et al. 2016a, b). The efficient and cost-effective methods for oily water treatment have been focused on to satisfy the stringent regulatory standards implemented in different countries (Ahmadun et al. 2009; Masuelli et al. 2009; Nandi et al. 2010; Amani and Kariminezhad 2016; Lv et al. 2017; Klymenko et al. 2017; Huang et al. 2018; Darvishzadeh et al. 2018; Nguyen et al. 2019; Thaís et al. 2019). DAF combined with chemicals is effective to remove low-density particles from oily water (Leonie and Sarubbo 2018). Generally, it is believed that chemical pretreatment is essential for a high efficiency in

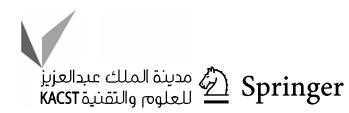


DAF (Al-Sabagh et al.2015; Leonie and Sarubbo 2018). Non-ionic surfactants were often used in oily wastewater treatment (Abedi and Nekouei 2011; Zhang et al. 2014; Souza et al. 2017), especially for removal of emulsified oil from gas condensate oil-water emulsion (Al-Sabagh et al. 2015). Certain characteristic properties of non-ionic surfactants for instance, its non-volatility, temperature and environment-friendly surfactant (Sarmah et al. 2020) and stable at high salinity (Lawson 1978) make it more efficient and feasible for field application.

Gas condensate oil reservoirs are an important source of oil and gas supply in China. The work for removing emulsified oil from gas condensate oil-water emulsion from $N$ oilfield is important and necessary to satisfy the stringent regulatory standards implemented in China. In order to obtain effective and economical chemical agents for treatment of oily water from $N$ oilfield, the paper studied the effects of oil composition and its characteristics (density, solubility) on removing emulsified oil from gas condensate oil-water emulsion for the first time. The component characterization of $N$ oilfield crude oil was carried out with gas chromatography-mass spectrometry. The density and solubility in water for some components were figured out to explain the extreme difficult for oil removal. Optimization of non-ionic surfactants combined with DAF for oil removal was investigated.

\section{Materials and instruments}

\section{Artificial brine}

The composition of formation brine in $N$ oilfield is shown in Table 1. The artificial simulation water based on the composition of the formation brine in $N$ oilfield was prepared and used for preparing the simulated solution in this research.

\section{Dehydrated crude oil}

The dehydrated crude oil from $N$ oilfield was used as the oil phase in the oil-water emulsion. The density of dehydrated crude oil at $56^{\circ} \mathrm{C}$ was measured by DMA 45 densitometer made by Anton Paar Company, Austria. The density of the oil is $0.8571 \mathrm{~g} / \mathrm{cm}^{3}$ at $56{ }^{\circ} \mathrm{C}$.

\section{Chemicals}

The chemicals used in the experiment such as $\mathrm{NaOH}$ ( $\geq 99.5 \%), \mathrm{NaHCO}_{3}(\geq 99.5 \%), \mathrm{Na}_{2} \mathrm{CO}_{3}(\geq 99.5 \%), \mathrm{NaCl}$ (>99.5\%), $\mathrm{KCl}(>99.5 \%), \mathrm{CaCl}_{2}(>96 \%), \mathrm{MgCl}_{2} \cdot 6 \mathrm{H}_{2} \mathrm{O}$ $(>99 \%)$ and $n$-Hexane (>99.5\%) are provided by Beijing Modern East Fine Chemical Co..

Non-ionic surfactants: $N I S_{1}, N I S_{2}$ and $N I S_{3}$.

\section{Instruments}

Gas chromatography-mass spectrometry (GC-MS) 7890B5977 (Agilent Technologies Inc., USA), TD-500D Oil Analyzer (Turner Designs, USA) and WPB05 Waring Blender (Waring Commercial, USA) were hired in experiments.

Dissolved air flotation instrument was a self-made device. The parameters (e.g., chemical concentration, feed rate and working pressure) effecting on the flotation efficiency for removing of the oil can be adjusted by the experimenter.

\section{Experiments}

\section{Gas chromatography-mass spectrometry of crude oil}

Component characterization of $N$ oilfield crude oil was carried with GC-MC.

\section{GC conditions}

The oven temperature was programmed from $80{ }^{\circ} \mathrm{C}$ (isothermal for $3 \mathrm{~min}$ ), with an increase of $5{ }^{\circ} \mathrm{C} / \mathrm{min}$, to $230{ }^{\circ} \mathrm{C}$ (isothermal for $1 \mathrm{~min}$ ), then $4{ }^{\circ} \mathrm{C} / \mathrm{min}$ to $280{ }^{\circ} \mathrm{C}$, ending with a 4 min isothermal at $280{ }^{\circ} \mathrm{C}$. The temperature of the injector was $250{ }^{\circ} \mathrm{C}$. Helium was the carrier gas, and split ratio was 20:1.

\section{MC conditions}

The spectrometers were operated in electron-impact (EI) mode, the scan range was 20-600 amu, the ionization energy was $70 \mathrm{eV}$ and the scan rate was $3.8 \mathrm{scan} / \mathrm{s}$. The ionization source temperature was $230{ }^{\circ} \mathrm{C}$, and the solvent delay was 2 min.
Table 1 Ion composition of formation brine in $N$ field

\begin{tabular}{lllllllll}
\hline Ions & $\mathrm{K}^{+}+\mathrm{Na}^{+}$ & $\mathrm{Ca}^{2+}$ & $\mathrm{Mg}^{2+}$ & $\mathrm{CO}_{3}^{2-}$ & $\mathrm{HCO}_{3}^{-}$ & $\mathrm{SO}_{4}{ }^{2-}$ & $\mathrm{Cl}^{-}$ & Total \\
\hline Concentration $(\mathrm{mg} / \mathrm{L})$ & 2288.12 & 28.74 & 55.48 & 227.7 & 1314.99 & 117.34 & 2620.24 & 6652.62 \\
\hline
\end{tabular}




\section{Oil removal from oily water}

Similar to the experimental method in previous studies (Lv et al. 2017), the oil was extracted from oily water with n-Hexane and then measure by TD-500D oil analyzer to get oil content for individual oily water. The oil content for oily water from $N$ oilfield without any treatment, for that from treatment of DAF without any chemicals, and for that from treatment of DAF combined with chemicals was measured, respectively. The effect of three non-ionic surfactants (NIS1, NIS2 and NIS3) with the same concentration of $600 \mathrm{mg} / \mathrm{L}$ on removing the emulsified oil in the DAF progress was studied. The concentration influence of the best surfactant on removing the emulsified oil was studied with different concentration $(600 \mathrm{mg} / \mathrm{L}, 800 \mathrm{mg} / \mathrm{L}$, $1000 \mathrm{mg} / \mathrm{L}, 1200 \mathrm{mg} / \mathrm{L}$ and $1500 \mathrm{mg} / \mathrm{L}$ ).

Artificial brine and $N$ oilfield crude oil were used to prepare oily water. The artificial brine and dehydrated $N$ oilfield crude oil were heated in a water bath at $56{ }^{\circ} \mathrm{C}$, respectively. Initial artificial oily water was prepared by adding crude oil to the artificial brine according to the oil content predetermined above, and then the mixture was blended at $5000 \mathrm{r} / \mathrm{min}$ for $15 \mathrm{~min}$ in waring blender shear emulsifier.
Feed rate, $\mathrm{pH}$ for oily water and working, pressure in DAF progress were $50 \mathrm{ml} / \mathrm{s}, 6$ and $0.2 \mathrm{MPa}$, respectively, according to previous optimization. The non-ionic surfactants with different concentrations for removal of oil from oily water were performed in DAF progress by adding surfactants to oily water before DAF started working. The oily water was kept in DAF tank for 10 min before samples were taken for analysis. 15 milliliters of clarified water were collected from the middle layer, which is between the float layer and $10 \mathrm{~cm}$ above the base.

\section{Results and discussion}

\section{Components of crude oil}

The GC-MC spectrometry of crude oil was shown in Fig. 1.

The retention time, peak area, the name of the compound and the molecular formula of the main compounds of crude oil were shown in Table 2.

The GC-MS analysis result showed the crude oil consisted of nine major components which counted for $96.4 \%$ of the total composition: toluene, 2-methylnaphthalene, naphthalene, trimethylbenzene, 1,4-xylene, 1-methylnaphthalene,

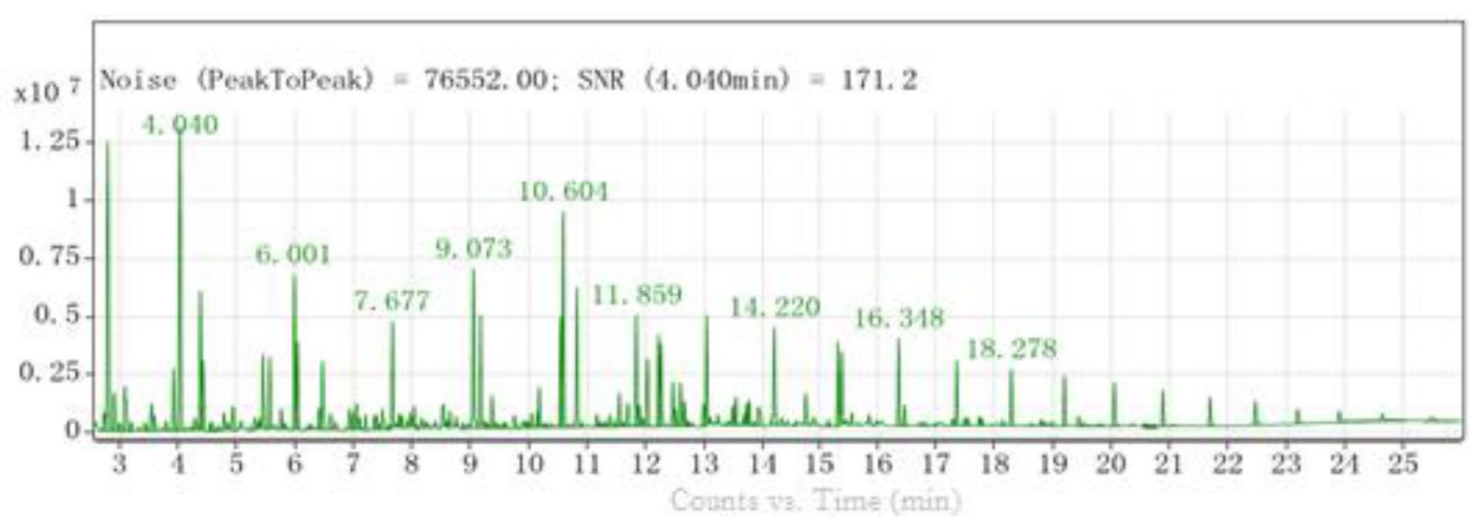

Fig. 1 The GC-MC spectrometry of crude oil

Table 2 The retention time, peak area, the name of the compound and the molecular formula and the proportion of the main compounds of crude oil

\begin{tabular}{lcrllc}
\hline S. no & Retention time & Peak area & The name of the compound & Molecular formula & Proportion \% \\
\hline 1 & 2.8 & 24487229.21 & Toluene & $\mathrm{C}_{6} \mathrm{H}_{6}$ & 20 \\
2 & 4.388 & 9953721.93 & 1-Methylnaphthalene & $\mathrm{C}_{11} \mathrm{H}_{10}$ & 10 \\
3 & 6.001 & 11035638.94 & Trimethylbenzene & $\mathrm{C}_{9} \mathrm{H}_{12}$ & 10.4 \\
4 & 9.073 & 13124003.23 & Naphthalene & $\mathrm{C}_{10} \mathrm{H}_{8}$ & 12 \\
5 & 9.187 & 7541440.83 & n-Dodecane & $\mathrm{C}_{12} \mathrm{H}_{26}$ & 9 \\
6 & 10.604 & 15369301.49 & 2-Methylnaphthalene & $\mathrm{C}_{11} \mathrm{H}_{10}$ & 14 \\
7 & 10.842 & 10175251.2 & 1,4-Xylene & $\mathrm{C}_{8} \mathrm{H}_{10}$ & 7 \\
8 & 11.859 & 7231262.88 & n-Tetradecane & $\mathrm{C}_{14} \mathrm{H}_{30}$ & 7 \\
9 & 13.063 & 7181875.3 & n-Pentadecane & $\mathrm{C}_{15} \mathrm{H}_{32}$ & 7 \\
\hline
\end{tabular}


n-dodecane, n-tetradecane and n-Pentadecane with proportion of $20 \%, 14 \%, 12 \%, 10.4 \%, 10 \%, 9 \%, 7 \%, 7 \%$ and $7 \%$, respectively.

\section{Oil content of oily water before and after DAF without any chemicals}

Oil content of oily water from $N$ oilfield before and after DAF without any chemicals was $5285.95 \mathrm{mg} / \mathrm{L}$ and $895.53 \mathrm{mg} / \mathrm{L}$, respectively, while the later one can't meet the requirement prescribed by the People's Republic of China (PRC) (Lv et al. 2017). Obviously oil-water separation was hard, which can be explained from the oil density and solubility of oil in water.

The density and solubility for the first four compounds in $N$ oilfield crude oil and normal alkanes with the same number of carbon atoms as comparison were shown in Table 3 .

First, Table 3 shows the density of each compound is larger than that of each relative normal alkane with the same number of carbon atoms, so for the first four compounds which make up 50\% of the total composition, the density difference between water and each individual compound is smaller than the difference between water and normal alkanes with the same number of carbon atoms. Since density difference is an important parameter affecting oil-water separation as discussed by Adewunmi (2019), the remarkable density difference between $N$ oilfield oil and water enhanced the oil-water separation difficulty in DAF progress, which is consistent with Murakami's work (Murakami et al. 2014). Reduced density difference between oil-water phases helps to prevent oil droplet as well as air-water surface and oil droplet from coalescence, and vice versa (Adewunmi 2019).

Second, oil can exist as free, dispersed, emulsified or soluble form in oily water. The removal methods and difficulty of these four kinds of oil are obviously different. Free oil is non-dispersed and floats on the surface, which can be skimmed off. Non-emulsified dispersed oil can be removed by gravity separation ( $\mathrm{Li}$ et al. 2015). The first two kinds of oil were removed in DAF progress without any chemicals. The removal of dissolved oil is difficult, and the commonly used methods are membrane separation method, adsorption method and biological method (Qiang 2012). It can be seen from Table 3 that the solubility of these four compounds in water is greater than that of normal alkanes with the same number of carbon atoms. The solubility properties of these four compounds enhanced the oil-water separation difficulty in DAF progress. The emulsified oil was the main target of the DAF process with chemicals (Takahashi et al. 1979). Through the combined use of DAF and chemical agents, the emulsified oil in the water is removed and the oil content in the water is reduced as much as possible.

\section{Non-ionic surfactants removing emulsified oil}

Effect of three non-ionic surfactants $\left(N I S_{1}, N I S_{2}\right.$ and $\left.N I S_{3}\right)$ with the same concentration of $600 \mathrm{mg} / \mathrm{L}$ on removing emulsified oil in DAF progress was shown in Table 4.

According to the result in Table 4, among three surfactants, $N I S_{1}$ with $600 \mathrm{mg} / \mathrm{L}$ could get a lowest residual oil content of $69.6 \mathrm{mg} / \mathrm{L}$, which was still higher than $10 \mathrm{mg} / \mathrm{L}$ prescribed by PRC (Lv et al. 2017).

Table 4 Effect of the three non-ionic surfactants on removing of emulsified oil

\begin{tabular}{lll}
\hline \multirow{2}{*}{$\begin{array}{l}\text { Non-ionic } \\
\text { surfactants }\end{array}$} & \multicolumn{2}{l}{ Emulsified oil (mg/L) } \\
\cline { 2 - 3 } & $\begin{array}{l}\text { DAF treatment } \\
\text { with surfactants }\end{array}$ & DAF treatment without any chemical \\
\hline$N I S_{1}$ & 69.6 & 895.53 \\
$N I S_{2}$ & 136.5 & \\
$N_{2}$ & 101.8 & \\
\hline
\end{tabular}

Table 3 The density and solubility in water of the first four compounds and normal alkanes with the same number of carbon atoms

\begin{tabular}{llll}
\hline Chemicals & Chemical formula & Density $(\mathrm{g} / \mathrm{mL})$ & $\begin{array}{l}\text { Solubility in water } \\
\left(\mathrm{g} / 100 \mathrm{ml}, 25^{\circ} \mathrm{C}\right)\end{array}$ \\
\hline Toluene & $\mathrm{C}_{6} \mathrm{H}_{6}$ & $0.8623\left(25^{\circ} \mathrm{C}\right)$ & $5.19 \mathrm{E}-02$ \\
Neohexane & $\mathrm{C}_{6} \mathrm{H}_{14}$ & $0.6444\left(25^{\circ} \mathrm{C}\right)$ & $3.32 \mathrm{E}-03$ \\
2-Methylnaphthalene & $\mathrm{C}_{11} \mathrm{H}_{10}$ & $1.0058\left(20^{\circ} \mathrm{C}\right)$ & $2.50 \mathrm{E}-03$ \\
Hendecane & $\mathrm{C}_{11} \mathrm{H}_{24}$ & $0.7402\left(20^{\circ} \mathrm{C}\right)$ & $2.42 \mathrm{E}-04$ \\
Naphthalene & $\mathrm{C}_{10} \mathrm{H}_{8}$ & $1.1620^{\triangle}\left(20^{\circ} \mathrm{C}\right)$ & $7.00 \mathrm{E}-08$ \\
Decane & $\mathrm{C}_{10} \mathrm{H}_{22}$ & $0.7300^{\square}\left(20^{\circ} \mathrm{C}\right)$ & $1.50 \mathrm{E}-06$ \\
Trimethylbenzene & $\mathrm{C}_{9} \mathrm{H}_{12}$ & $0.8652^{\triangle}\left(20^{\circ} \mathrm{C}\right)$ & $7.00 \mathrm{E}-03$ \\
Nonane & $\mathrm{C}_{9} \mathrm{H}_{20}$ & $0.7176^{*}\left(20^{\circ} \mathrm{C}\right)$ & $1.70 \mathrm{E}-05$ \\
\hline
\end{tabular}

Data without any symbol from Haynes (2016); Data with the triangle symbol $\left({ }^{\Delta}\right)$ from "Hazardous Substances Data Bank" which obtained from the National Library of Medicine (US); Date with the square symbol ( ${ }^{\square}$ ) from Fengjun et al. (2008); Date with the star symbol (*) from Kirss et al. (2008) 


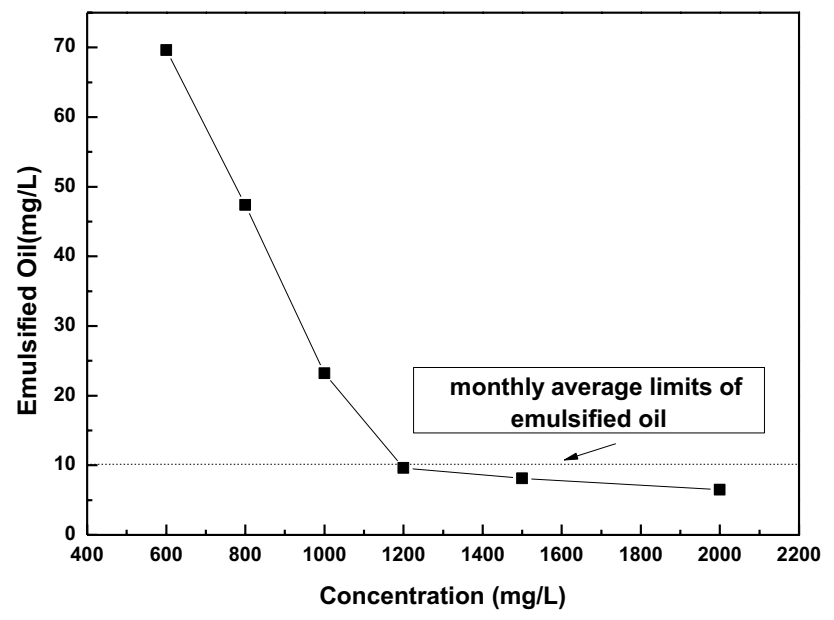

Fig. 2 Influence of the concentration of $N I S_{1}$ on the removing of emulsified oil

Non-ionic surfactants were often used in oily wastewater treatment (Abedi and Nekouei 2011; Zhang et al. 2014; Souza et al. 2017). These non-ionic surfactants modified the liquid/liquid and liquid/air surface properties, and served to decrease the interfacial tension between the dispersed oil phase and the oily water, and to increase the interfacial tension between the air bubbler and the oil phase. Consequently, non-ionic surfactants were effective for removal of emulsified oil in oily water in DAF progress (Al-Sabagh et al. 2015). Dai and Zhao (2018) suggested a mechanism to explain the effect of surfactants on oil-water separation, in which the surfactant molecular can replace the original adsorption film, and weaken its protection on the surface of oil droplets, make oil droplets easier to aggregate to form oil layer, and be separated from wastewater finally.

The influence of $N I S_{1}$ concentration on oil removal is shown in Fig. 2.

With the increase in $N I S_{1}$ concentration from 400 to $1200 \mathrm{mg} / \mathrm{L}$, the residual emulsified oil content was decreased significantly from 70 to $9.6 \mathrm{mg} / \mathrm{L}$, the latter of which can meet the requirement prescribed by PRC similar to the previous results ( $\mathrm{Lv}$ et al. 2017). More increase of $N I S_{1}$ concentration only generates minor change of oil content from 8.1 to $6.5 \mathrm{mg} / \mathrm{L}$, so $1200 \mathrm{mg} / \mathrm{L} N I S_{1}$ was the optimized formulation for emulsified oil removal from $\mathrm{N}$ oilfield oily water. The effect of surfactant concentration on the residual emulsified oil content was similar to study of Mhatre et al. (2018). Mhatre studied the effect of various chemical demulsifiers to the electrocoalescence process in emulsion which determined the stability of the emulsion. They found the chemical agent gave a tremendous effect to the stability of the emulsion at the first phase. They also pointed out that demulsifiers contain concentration limit. Because when the concentration of demulsifiers reached certain value, the raising of the demulsifiers concentration did not enhance the electrocoalescence process. $1200 \mathrm{mg} / \mathrm{L}$ was the critical point of concentration in this paper which was similar to the concentration limit in the study of Mhatre.

\section{Conclusion}

1. Based on the GC-MS analysis, the crude oil consisted of nine major components which counted for $96.4 \%$ of the total composition, and the first four compounds made up $50 \%$ of the total composition.

2. For the first four compounds, the density difference between water and each individual compound is smaller than the difference between water and normal alkanes with the same number of carbon atoms, while the solubility of these four compounds in water is greater than that of normal alkanes with the same number of carbon atoms. The characteristic of both density and solubility of the crude oil increased the oil-water separation difficulty in DAF progress.

3. Oil content of oily water from $N$ oilfield before and after DAF without any chemicals was $5285.95 \mathrm{mg} / \mathrm{L}$ and $895.53 \mathrm{mg} / \mathrm{L}$, respectively, while the later one can't meet the requirement prescribed by PRC.

4. Among three surfactants, $N I S_{1}$ with $600 \mathrm{mg} / \mathrm{L}$ could get a lowest residual oil content, and $1200 \mathrm{mg} / \mathrm{L} \mathrm{NIS} S_{1}$ was the optimized formulation for emulsified oil removal from $N$ oilfield oily water.

Open Access This article is licensed under a Creative Commons Attribution 4.0 International License, which permits use, sharing, adaptation, distribution and reproduction in any medium or format, as long as you give appropriate credit to the original author(s) and the source, provide a link to the Creative Commons licence, and indicate if changes were made. The images or other third party material in this article are included in the article's Creative Commons licence, unless indicated otherwise in a credit line to the material. If material is not included in the article's Creative Commons licence and your intended use is not permitted by statutory regulation or exceeds the permitted use, you will need to obtain permission directly from the copyright holder. To view a copy of this licence, visit http://creativecommons.org/licenses/by/4.0/.

\section{References}

Abdol HR, Kassim WM, El HA, El-Jawashi SA (2008) Risk assessment and remediation suggestion of impacted soil by produced water associated with oil production. Environ Sci Technol 145(3):95-102

Abedi S, Nekouei F (2011) Removal of direct yellow 12 from water samples by cloud point extraction using triton $\mathrm{x}-100$ as nonionic surfactant. J Chem 8(4):1588-1595 
Adewunmi AA, Kamal MS (2019) Demulsification of water-in-oil emulsions using ionic liquids: effects of counterion and water type. J Mol Liq 279:411-419. https://doi.org/10.1016/j.molli q.2019.02.008

Ahmadun FR, Pendashteh A, Abdullah LC, Biak DRA, Madaeni SS, Abidin ZZ (2009) Review of technologies for oil and gas produced water treatment. J Hazard Mater 170(2):530-551

Al-Sabagh AM, Sharaky AM, Noor El-Din MR, Hussein KM (2015) Destabilization of gas condensate oil-water emulsion by dissolved air flotation using new non ionic surfactants. Tenside Surfactants Deterg 52(1):88-98

Amani H, Kariminezhad H (2016) Study on emulsification of crude oil in water using emulsion biosurfactant for pipeline transportation. Pet Sci Technol 34(3):216-222

Dai CL, Zhao FL (2018) Oilfield wastewater treatment. In: Dai CL, Zhao F (eds) Oilfield chemistry. Springer, Singapore, pp 373-390

Darjani S, Koplik J, Pauchard V (2017) Extracting the equation of state of lattice gases from random sequential adsorption simulations by means of the gibbs adsorption isotherm. Phys Rev E 96(5):052803

Darjani S, Koplik J, Banerjee S, Pauchard V (2019) Liquid-hexaticsolid phase transition of a hard-core lattice gas with third neighbor exclusion. J Chem Phys 151(10): 104702

Darvishzadeh T, Bhattarai B, Priezjev NV (2018) The critical pressure for microfiltration of oil-in-water emulsions using slotted-pore membranes. J Membr Sci 563:610-616

Haynes WM (2016) CRC handbook of chemistry and physics, 97th edn. CRC Press, Florida

Hazardous Substances Data Bank:naphthalene\&trimethylbenzene. National Library of Medicine, Bethesda, MD

Huang S, Ras RHA, Tian X (2018) Antifouling membranes for oily wastewater treatment: interplay between wetting and membrane fouling. Curr Opin Colloid Interface Sci. https://doi.org/10.1016/j. cocis.2018.02.002

Kirss H, Kuus M, Siimer E (2008) Isobaric vapor-liquid equilibria of the ternary system 1-pentanol + nonane + anisole. J Chem Eng Data 53(1):310-314

Klymenko NY, Siora IV, Novikova EA et al (2017) Destruction of hydrocarbons by the composite system based on the nanosilicas and yeast cells mixture in aqueous medium. J Water Chem Technol 39(4):209-213

Lawson JB (1978) The adsorption of non-ionic and anionic surfactants on sandstone and carbonate. In: SPE symposium on improved methods of oil recovery. SPE Journal. https://doi. org/10.2118/7052-ms

Li X, Liu J, Wang Y, Xu H, Cao Y, Deng X (2015) Separation of oil from wastewater by coal adsorption-column flotation. Sep Sci Technol 504:583-591

Lv P, Wang XP, Chen YB, Guo XX, Xu AG, Zhao ZQ (2017) Optimization of chemical agents for removing dispersed oil from produced water in $Z$ oilfield. Pet Sci Technol 35(12):1285-1289

Masuelli M, Marchese J, Ochoa NA (2009) SPC/PVDF membranes for emulsified oily wastewater treatment. J Membr Sci 326(2):688-693

Mhatre S, Simon S, Sjöblom J, Xu Z (2018) Demulsifier assisted film thinning and coalescence in crude oil emulsions under DC electric fields. Chem Eng Res Des 134:117-129. https://doi.org/10.1016/j. cherd.2018.04.001

Mozaffari S (2015) Rheology of Bitumen at the onset of asphaltene aggregation and its effects on the stability of water-in-oil emulsion. University of Alberta, Edmonton
Mozaffari S, Tchoukov P, Atias J, Czarnecki J, Nazemifard N (2015) Effect of asphaltene aggregation on rheological properties of diluted athabasca bitumen. Energy Fuels 29:5595-5599. https:// doi.org/10.1021/acs.energyfuels.5b00918

Mozaffari A, Sharifi-Mood N, Koplik J, Maldarelli C (2016a) Selfdiffusiophoretic colloidal propulsion near a solid boundary. Phys Fluids 28(5):053107

Mozaffari S, Tchoukov P, Mozaffari A, Atias J, Czarnecki J, Nazemifard N (2016b) Capillary driven flow in nanochannels-application to heavy oil rheology studies. Colloids Surf A 513:178-187

Mozaffari S, Li W, Mudit D, Soenke S, Byeongdu L, Libor K et al (2019) The role of nanoparticle size and ligand coverage in size focusing of colloidal metal nanoparticles. Nanoscale Adv 2019(1):4052-4066

Murakami R, Moriyama H, Noguchi T, Yamamoto M, Binks BP (2014) Effects of density difference between water and oil on stabilization of powdered oil-in-water emulsions. Langmuir 30(2):496-500

Nandi BK, Moparthi A, Uppaluri R, Purkait MK (2010) Treatment of oily wastewater using low cost ceramic membrane: comparative assessment of pore blocking and artificial neural network models. Chem Eng Res Des 88(7):881-892

Nguyen DD, Vu C, Choi HJ, Thi VH (2019) Micron-size white bamboo fibril-based silane cellulose aerogel: fabrication and oil absorbent characteristics. Mater. https://doi.org/10.3390/ma12091407

Qiang CC (2012) Pilot study of MABR for the treatment of oilfield wastewater. Dissertation, Tianjin University

Raya SA, Mohd SI, Abbas AA et al (2020) A critical review of development and demulsification mechanisms of crude oil emulsion in the petroleum industry. J Petrol Explor Prod Technol 10:17111728. https://doi.org/10.1007/s13202-020-00830-7

Sarmah S, Gogoi SB, Xianfeng F et al (2020) Characterization and identification of the most appropriate nonionic surfactant for enhanced oil recovery. J Petrol Explor Prod Technol 10:115-123. https://doi.org/10.1007/s13202-019-0682-1

Sarubbo LA (2018) Dissolved air flotation combined to biosurfactants: a clean and efficient alternative to treat industrial oily water. Rev Environ Sci Bio/Technol 17:591-602

Souza AV, Mendes M, Souza STS, Palermo LCM, Oliveira EPF, Mansur CRE (2017) Synthesis of additives based on polyethylenimine modified with nonionic surfactants for application in phase separation of water-in-oil emulsions. Energy Fuels. https://doi. org/10.1021/acs.energyfuels.7b01730

Takahashi T, Miyahara T, Nishizaki Y (1979) Separation of oily water by bubble column. J Chem Eng Jpn 12(5):394-399

Thaís AO, Ivison AS, Attilio C, Leonie AS (2019) Production and formulation of a new low-cost biosurfactant to remediate oilcontaminated seawater. J Biotechnol 295:71-79

Yang F, Guo Y, Xing Y (2008) Densities and viscosities of binary mixtures of JP-10 with n-octane or n-decane at several temperatures. J Chem Eng Data 53(9):2237-2240

Zhang J, Jing B, Ma Y, Duan M, Fang S (2014) The phase inversion properties of a non-ionic surfactant and its performance for treatment of oily wastewater produced from polymer flooding. Sep Sci Technol. https://doi.org/10.1080/01496395.2014.942784

Publisher's Note Springer Nature remains neutral with regard to jurisdictional claims in published maps and institutional affiliations. 